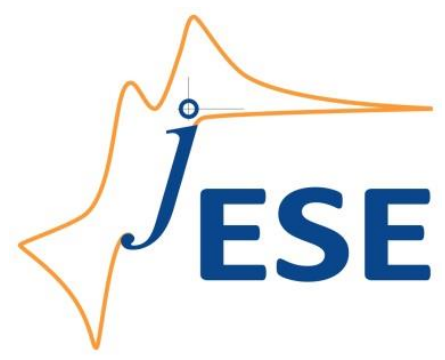

Open Access : : ISSN 1847-9286

www.jESE-online.org

Original scientific paper

\title{
Influence of ceramic separator's characteristics on microbial fuel cell performance
}

\author{
Anil N. Ghadge, Mypati Sreemannarayana, Narcis Duteanu* and \\ Makarand M. Ghangrekar ${ }^{\bowtie}$
}

Department of Civil Engineering, Indian Institute of Technology, Kharagpur -721302, India

*University "Politehnica" of Timisoara, Industrial Chemistry and Environmental Engineering,

2 Victoria Sq., 300006 Timisoara, Romania

${ }^{\square}$ Corresponding Author: ghangrekar@civil.iitkgp.ernet.in; Tel.: +91-3222-283440

Received: January 27, 2013; Revised: February 15, 2014; Published: December 6, 2014

\begin{abstract}
This study aimed at evaluating the influence of clay properties on the performance of microbial fuel cell made using ceramic separators. Performance of two clayware microbial fuel cells (CMFCs) made from red soil (CMFC-1) typically rich in aluminum and silica and black soil (CMFC-2) with calcium, iron and magnesium predominant was evaluated. These MFCs were operated under batch mode using synthetic wastewater. Maximum sustainable volumetric power density of $1.49 \mathrm{~W} \mathrm{~m}^{-3}$ and $1.12 \mathrm{~W} \mathrm{~m}^{-3}$ was generated in CMFC-1 and CMFC-2, respectively. During polarization, the maximum power densities normalized to anode surface area of $51.65 \mathrm{~mW} \mathrm{~m}^{-2}$ and $31.20 \mathrm{~mW} \mathrm{~m}^{-2}$ were obtained for CMFC-1 and CMFC-2, respectively. Exchange current densities at cathodes of CMFC-1 and CMFC-2 are 3.38 and 2.05 times more than that of respective anodes, clearly indicating that the cathodes supported much faster reaction than the anode. Results of laboratory analysis support the presence of more number of exchangeable cations in red soil, representing higher proton exchange capacity of CMFC-1 than CMFC-2. Higher power generation was observed for CMFC-1 with separator made of red soil. Hence, separators made of red soil were more suitable for fabrication of MFC to generate higher power.
\end{abstract}

\section{Keywords}

Cation exchange capacity; Coulombic efficiency; Charge transfer resistance; Charge transfer coefficient; Exchange current density; Power density; Wastewater treatment

\section{Introduction}

Recently considerable attention is being paid on the two major problems of the world, which are namely maintaining quality of water body and energy crisis. Solution to these problems could be provided by microbial fuel cell (MFC) to treat organic matter present in wastewater and 
simultaneously produce bio-electricity [1-5]. Although, considerable progress has been achieved in the performance of a MFC in the past ten years, one of the main challenge for commercializing scalable MFCs is the high cost and low mechanical strength of the separator materials used for fabrication of this device. Tian et al. [6], demonstrated that placing of an anaerobic membrane filtration process sequentially with an MFC accomplished efficient nutrients removal with low propensity of membrane fouling. It was reported that the use of poly(tetrafluoro-ethylene) (PTFE) layered activated charcoal electrode and Zirfon ${ }^{\circledR}$ as separator, improved MFCs performance and can be used to replace costly polymeric membrane and expensive catalyst in MFCs [7]. Proton exchange membrane (PEM) such as Nafion [8], nano-composite membrane made of sulfonated polymer (ether ether ketone) and Montmorillonite Clay [9], nano-composite membranes of Nafion and montmorillonite clay [10] were used in the MFCs to separate anodic chamber from cathodic chamber. However, these polymeric membranes or composite membranes are costly; hence, limit the practical application of the MFCs.

Ceramic membranes are found to be promising materials in MFCs because of their low production cost and better structural strength, thus, providing an alternative for the costly polymeric membranes [11-15]. Application of such ceramic membranes in MFC has been practiced since last ten years and its utility has been demonstrated through different studies. This was the first attempt where Park and Zeikus [11] developed a porcelain septum separator for single chambered MFC using 100\% Kaolin and found comparable performance with that dual chambered MFC. A three layered cathode composed of a cellulose acetate film, a ceramic membrane, and a porous graphite plate to create a single chamber MFC that linked with solar cell to enhance power generation [12]. Behera and Ghangrekar [13] studied the effect of different thickness of such ceramic membrane on performance of the dual chambered MFC, and reported better power output for MFC having smallest thickness of the membrane. Use of terracotta pot for making single chamber MFC, after coating outer surface with conductive graphite paint, demonstrated Coulombic efficiency of $21 \pm 5 \%$ with power density of $33.13 \mathrm{~mW} \mathrm{~m}^{-2}$ [14]. More recently, Winfield et al. [15] compared performance of MFCs made from terracotta and earthenware by considering wall thickness, porosity and cathode hydration. More porosity of earthenware proved to be the better material compared to terracotta. However, these studies do not include the effect of soil $\mathrm{pH}$, conductivity and cation exchange capacity (CEC) on the performance of MFCs.

For effectual use of such ceramic membranes, made from clay minerals, they should have higher cation exchange capacity. The existence of the $\mathrm{pH}$ dependent charge portion of the cation exchange capacity of soils is widely accepted for many years [16]. Electrical conductivity of the soil is the measure of salt concentration in the soil solution. Bulk electrical conductivity of soil is generally assumed to be dominated by the electrical conductivity of the soil solution, with perhaps a small contribution from surface charges associated with soil solids [17].

In MFCs, the rate of proton consumption at the cathode is often higher than the transfer rate through the membrane $[18,19]$. Hence, for enhancing power generation of this device the separator used should offer higher rate of proton/cation transfer. The transfer of protons from a protonated species to an uncharged molecule at the surface of the clay mineral is an important process [20]. The soil used for making ceramic separator in MFC participates in exchange of cations from anodic chamber to cathodic chamber. Protons released during the oxidation of organic matter from the anodic chamber are being adsorbed on to the surface of the soil by replacing the loosely held cations. The layered silicate clay minerals like smectite clays, show attractive hydrophilic properties and good thermal stability at high temperature [21]. The layered 
silicates commonly used for proton exchange membrane fuel cell applications are montmorillonite made of silica tetrahedral and alumina octahedral sheets which has advantageous hygroscopic properties [22,23]. The cations $\mathrm{Ca}^{2+}, \mathrm{Mg}^{2+}, \mathrm{K}^{+}$and $\mathrm{Na}^{+}$are called the base cations and $\mathrm{H}^{+}$and $\mathrm{Al}^{3+}$ are called acidic cations. The acidity of the soil is the amount of the total cation exchange capacity (CEC) occupied by the acidic cations [24]. More than proton, this cation migration also affects the performance of cathode, hence overall performance of MFC.

Porosity of the soil represents the hydraulic conductivity which depends upon the pore throat radii of clay materials. Typically clays have very low hydraulic conductivity due to their small throat radii. For MFC made with such clayware separator, different soil porosities play a vital role in the seepage of substrate from anodic to cathodic chamber [25]. Apart from loss of fuel, this may lead to the availability of organic matter at higher concentration on the cathode, supporting heterotrophic bacterial growth on cathode and thereby reducing cathode potential. Under such circumstances, the cathode often gives negative potentials ( $v s$. $\mathrm{Ag} / \mathrm{AgCl}$ ), than the positive potential it is expected to give, while using oxygen as an electron acceptor [26]. Hence, hydraulic conductivity and cation exchange capacity are the important properties of the materials to be selected as a separator in MFC.

The objective of this study was to investigate the effect of different soil properties like $\mathrm{pH}$, conductivity, porosity, cation exchange capacity on the performance of MFCs having ceramic separators made from two different soils. In addition, the electrode reaction kinetics was investigated for assessing performance of these MFCs.

\section{Experimental}

\section{Construction of Microbial Fuel Cell}

The study was carried out using dual-chambered Clayware Microbial Fuel Cells (CMFCs). The anodic chambers of these CMFCs were made up of baked clayware pot and the wall material of the pot (about $5 \mathrm{~mm}$ thick) itself acted as a separator allowing transfer of protons from anode to cathode. The pots were made from the red soil (typically rich in aluminum and silica) in CMFC-1 and black soil (rich in calcium, iron and magnesium predominant) in CMFC-2. The anodic chamber of the CMFC-1 and CMFC-2 had a liquid volume capacity of $550 \mathrm{ml}$ and $700 \mathrm{ml}$, respectively. Cathodic chambers in both the MFCs were made up of plastic container having 5 liter capacity. Although there is difference in anodic chamber volume of both the MFCs, however, cathodic chamber volume of 5 litre, which was kept same in both the MFCs. It is important to note here that the rate of proton transfer largely depends on the separator area to anodic chamber volume ratio $\left(S_{\mathrm{a}} / v\right)$. In the present study, this ratio was 83.3 and $86.5 \mathrm{~m}^{2} / \mathrm{m}^{3}$, respectively, for CMFC-1 (separator made of red soil) and CMFC-2 (separator made of black soil), which indicates that there was no significant difference in $S_{a} / v$ ratio. Carbon Felt (Panex ${ }^{\circledR 35}$, Zoltek Corporation) with 230 $\mathrm{cm}^{2}$ and $261 \mathrm{~cm}^{2}$ projected surface areas were used as cathode in CMFC-1 and CMFC-2, respectively. Anodes in CMFC-1 and CMFC-2 were made from stainless steel mesh having total surface area of $268 \mathrm{~cm}^{2}$ and $304 \mathrm{~cm}^{2}$, respectively. An aquarium aerator was inserted at the bottom of cathodic chamber to supply air continuously with an aquarium air pump (SOBO Aquarium Pump, China). The connections between two electrodes were made with concealed copper wire through external resistance of $100 \Omega$. 


\section{Inoculation and operation of CMFCs}

Anaerobic mixed sludge collected from septic tank was used as an inoculum in the anodic chamber of the CMFCs. When mixed anaerobic sludge is used as source of inoculum, it contains both electrogenic as well as non-electrogenic (mostly methanogenic) bacteria. In the anodic chamber of MFC, it is necessary to dominate electrogenesis to obtain higher Coulombic efficiency. Methanogens in the MFCs compete for substrate and electrode space with electrogenic bacteria and reduce the power output. Therefore, the inoculum sludge was given a heat pre-treatment (heated at $100{ }^{\circ} \mathrm{C}$ for $15 \mathrm{~min}$ ) to suppress methanogens and required amount of sludge was added to the anodic chamber [27]. Synthetic wastewater containing sodium acetate as a source of carbon with chemical oxygen demand (COD) of about $3000 \mathrm{mg} \mathrm{L}^{-1}$ was used in this study. The sodium acetate medium was prepared by adding $3843 \mathrm{mg} \mathrm{L} \mathrm{L}^{-1} \mathrm{CH}_{3} \mathrm{COONa}, 4500 \mathrm{mg} \mathrm{L}{ }^{-1} \mathrm{NaHCO}_{3}$, $954 \mathrm{mg} \mathrm{L}^{-1} \mathrm{NH}_{4} \mathrm{Cl}, 81 \mathrm{mg} \mathrm{L}^{-1} \mathrm{~K}_{2} \mathrm{HPO}_{4}, 27 \mathrm{mg} \mathrm{L}^{-1} \mathrm{KH}_{2} \mathrm{PO}_{4}, 750 \mathrm{mg} \mathrm{L}^{-1} \mathrm{CaCl}_{2} .2 \mathrm{H}_{2} \mathrm{O}, 192 \mathrm{mg} \mathrm{L}^{-1}$ $\mathrm{MgSO}_{4} .7 \mathrm{H}_{2} \mathrm{O}$ and trace metals like $\mathrm{Fe}, \mathrm{Ni}, \mathrm{Mn}, \mathrm{Zn}, \mathrm{Co}, \mathrm{Cu}$, and $\mathrm{Mo}$ as per the composition given by [27]. The feeding frequency of 5 days was adopted. These CMFCs were operated at temperatures varying from 33 to $37{ }^{\circ} \mathrm{C}$ under batch mode. The $\mathrm{pH}$ of tap water used as catholyte remained in the range of 8.2-8.5; whereas, anolyte $\mathrm{pH}$ was in the range of 7.1-7.4.

\section{Analysis and calculations}

The $\mathrm{pH}$ and conductivity of anolyte and catholyte was measured using $\mathrm{pH}$ meter (Cyber Scan $\mathrm{pH}$ 620) and TDS meter (Cyber Scan CD 650, Eutech instruments, Singapore), respectively. COD concentrations were measured according to APHA standard methods [28], using closed reflux method. The performance of CMFCs was evaluated in terms of voltage $(U)$ and current $(I)$ measured using a digital multimeter with data acquisition unit (Agilent Technologies, Malaysia) and converted to power according to $P=U I$, where $P=$ power, $W ; I=$ current, $A$; and $U=$ voltage, $V$. Power density and power per unit volume were calculated by normalizing power to the anode surface area and net liquid volume of anodic chamber, respectively. The current density $i_{\mathrm{d}}$ was calculated using

$$
i_{\mathrm{d}}=\frac{U}{R_{\mathrm{ext}} A_{\mathrm{d}}}
$$

where, $R_{\text {ext }}$ is the external resistance $(\Omega)$ and $A_{d}\left(\mathrm{~m}^{2}\right)$ is the surface area of the anode. Polarization studies were carried out by varying the external resistance from 10000 to $10 \Omega$ using the resistance box (GEC 05 R Decade Resistance Box) and cell voltages $(U)$ were recorded. Internal resistance of the CMFCs was measured from the slope of the line from plot of voltage versus current [29]. Columbic Efficiency $(C E)$ was determined by integrating the current measured over time, $t$, and compared with the theoretical current on the basis of COD removal and calculated as [1]:

$$
C E=\frac{M \int_{0}^{t} / \mathrm{d} t}{F b V \triangle C O D}
$$

where, $V$ is the volume of the anodic chamber of MFC; $M=32$, molecular weight of oxygen; $F$, Faraday's constant $=96485 \mathrm{C} \mathrm{mol}^{-1} ; b=4$, the number of electrons exchanged per mole of oxygen; $\triangle C O D$ is the difference in the influent and effluent COD for time $t$. 


\section{Analysis of the soil properties}

The $\mathrm{pH}$ and the conductivity of the soil samples were measured according to the Indian Standard method of test for soils. Indian standard IS: 2720 (Part 26) - 1987 was used for determination of $\mathrm{pH}$ value [30] and conductivity of the soil was measured according to IS 14767: 2000 [31]. Cation exchange capacity of the soil was measured according to Indian standard, IS: 2720 (Part 24) - 1976 [32]. Chemical constituents for the red and black soils were obtained through the X-Ray Fluorescence (XRF) analysis. Porosity of the soil was indirectly measured from the percentage water absorbed by the clayware pot made from respective soils after immersing in water for 24 hours.

\section{Reaction kinetics at electrodes}

Tafel plot, as derived from equation (3) [33], was employed to measure the reaction kinetics for working electrode (anode and cathode) and $\mathrm{Ag} / \mathrm{AgCl}$ was used as the reference electrode. The reference electrode was placed in the working chamber during the measurements.

$$
\ln \left(\frac{i}{i_{0}}\right)=\beta\left(\frac{F \eta}{R T}\right)
$$

where $i_{0}$ is exchange current density, $i$ is the electrode current density ( $\left.\mathrm{mA} \mathrm{m} \mathrm{m}^{-2}\right), \alpha$ is the electron transfer coefficient, $R$ is the ideal gas constant $\left(8.31 \mathrm{~J} \mathrm{~mol}^{-1} \mathrm{~K}^{-1}\right), F$ is the Faraday's constant $(96,485$ $\left.\mathrm{C} \mathrm{mol}^{-1}\right), T$ is the absolute temperature, $\mathrm{K}$ and $\eta$ is the activation overpotential. Purpose of using Tafel plot is to calculate the $i_{0}$ and $\alpha$ value. The $i_{0}$ is a fundamental parameter in the rate of electro-oxidation or electro-reduction of a chemical species at an electrode at equilibrium. The charge transfer resistance $\left(R_{\mathrm{ct}}\right)$ was calculated from the following equation:

$$
R_{\mathrm{ct}}=\frac{R T}{n F i_{0}}
$$

where, $n$ is the number of electrons.

\section{Results and Discussion}

Physico-chemical properties of the soil used in CMFCs

The soils used for manufacturing the pots showed different $\mathrm{pH}$. The electrical conductivity and cation exchange capacity of the red soil is higher than that of the black soil, indicating usefulness of the former in the clayware separator application (Table 1). However, the porosity of the pot made from black soil was higher than the pot made from red soil. Higher porosity may allow the anolyte to come to the cathode resulting in not only the physical substrate loss but also it will allow oxygen to penetrate in anodic chamber, reducing Coulombic efficiency of the system due to direct oxidation of the substrate.

Table 1. Physical, chemical and electrical properties of red and black soil used for making separators

\begin{tabular}{clcc}
\hline SI. No & Soil properties & Red soil (CMFC-1) & Black soil (CMFC-2) \\
\hline 1 & $\mathrm{pH}$ & 7.4 & 8.5 \\
\hline 2 & Porosity, $\%$ & 11.6 & 17.6 \\
\hline 3 & Electrical conductivity, $\mathrm{mS} \mathrm{cm}^{-1}$ & 2.403 & 0.045 \\
\hline 4 & Cation exchange capacity (CEC), mmol (kg soil) $)^{-1}$ & 125 & 20 \\
\hline
\end{tabular}




\section{Wastewater treatment}

After inoculating the anodic chamber of the CMFCs with heat pretreated anaerobic mixed consortia, synthetic feed was supplied and wastewater treatment performance of the CMFCs under different feed cycles was observed. Average COD removal efficiency of $78.9 \pm 3.9 \%$ and $89.6 \pm 3.2 \%$ was observed in CMFC-1 and CMFC-2, respectively. COD removal efficiency in the CMFC-2 was higher than the CMFC-1. It was observed that porosity of clayware pot used in CMFC-2 was $52 \%$ higher (Table 1 ) than that of CMFC-1, because of which probably it has permitted more diffusion of oxygen from cathodic chamber to anodic chamber to support aerobic oxidation of fraction of substrate present in anodic chamber to establish higher COD removal efficiency. The oxygen diffusion coefficient in the range of $5.38 \times 10^{-6}$ to $6.67 \times 10^{-6} \mathrm{~cm}^{2} \mathrm{~s}^{-1}$ is reported in early studies for this clayware separator by Behera and Ghangrekar [13]. In addition, due to more porosity of separator used in CMFC-2, exchange of water molecules due to osmosis across the membrane might have diluted the anolyte, resulting in higher COD removal rate.

\section{Electricity generation}

Performance of CMFCs was evaluated by measuring the open circuit voltage and operating voltage. The current and voltage gradually increased with time of operation. The maximum voltage across $100 \Omega$ resistance of $286 \mathrm{mV}$ and $280 \mathrm{mV}$ was observed in CMFC-1 and CMFC-2, respectively. CMFC-1 generated a maximum sustainable power density (normalized to the anode surface area) and volumetric power (normalized to the working volume of anodic chamber) of $30.5 \mathrm{~mW} \mathrm{~m}^{-2}$ and $1.49 \mathrm{~W} \mathrm{~m}^{-3}$ (Fig. 1), respectively; whereas, CMFC-2 generated power density of $25.7 \mathrm{~mW} \mathrm{~m}^{-2}$ and volumetric power of $1.12 \mathrm{~W} \mathrm{~m}^{-3}$. The power produced by CMFC-1, made from red soil, was 1.33 times higher than the CMFC-2 wherein the separator was made from black soil with lower CEC and electrical conductivity. It is interesting to note here that in spite of having higher separator area and more liquid volume (anodic chamber) for CMFC-2, it generated less power compared to CMFC-1.

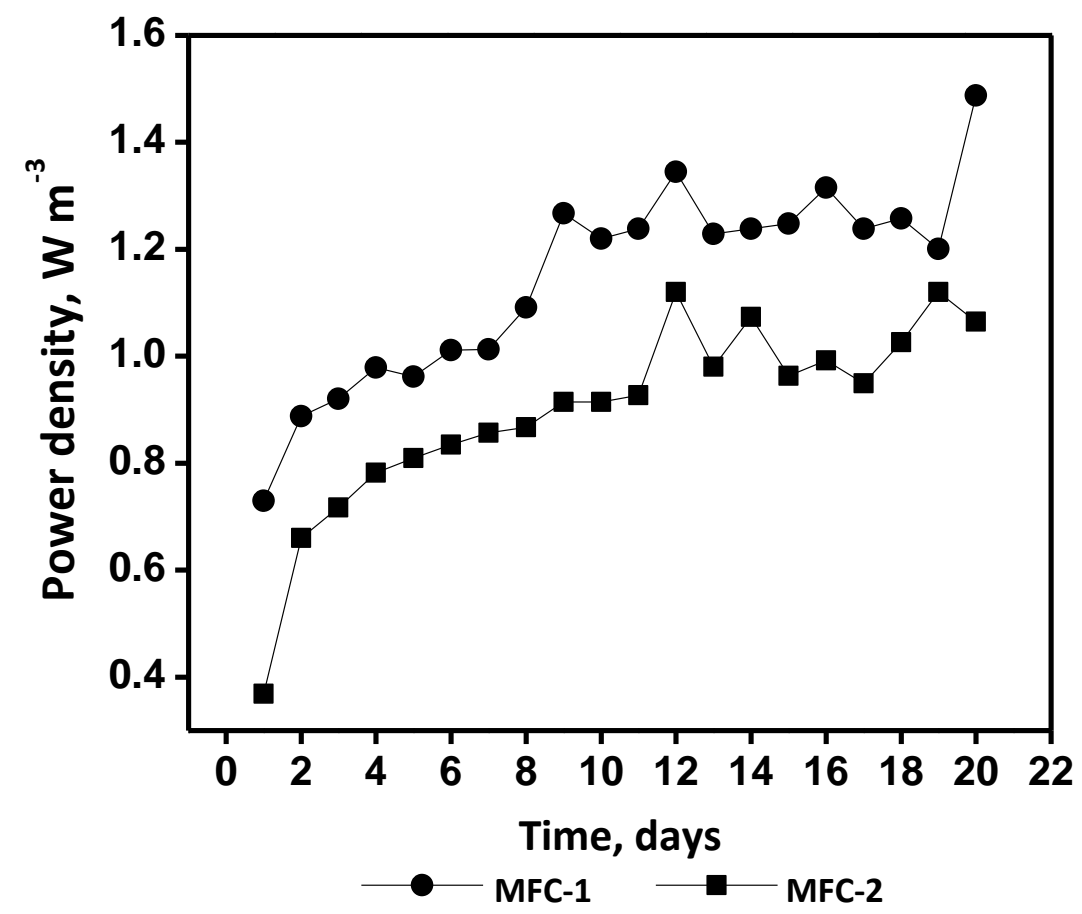

Figure 1. Volumetric power density of CMFC-1 and CMFC-2 


\section{Effect of chemical properties of soil used for making separator on electricity generation}

The CEC of red soil is 6.25 times (Table 1 ) higher than black soil, indicating more number of exchange sites are available for the transfer of cations in red soil. Due to availability of more exchange sites in CMFC-1, better transfer of the protons occurred to improve the power generation in CMFC-1 compared to CMFC-2. In addition, the XRF data (Table 2) confirms that the aluminum content of the red soil is more than the black soil which makes the red soil more acidic than black soil. The $\mathrm{pH}$ of the red soil (Table 1) was lower than black soil confirming that the red soil is more acidic and has high capacity to hold the $\mathrm{H}^{+}$ions which improved the performance of CMFC-1 in terms of power generation.

Electrical conductivity is the measure of salt concentration in the soil solution. Soils high in smectite often exhibit high electrical conductivity due to water associated with the clays. The soil with high montmorillonite mineral can act as better proton exchange material due to its hydrophilic nature and the high cation exchange capacity [34]. The conductivity of soil used as separator in CMFC-1 is almost 53.4 times (Table 1) more compared to CMFC-2, authenticating utility of the red soil for making separator to harvest more power from the CMFCs.

Table 2. Chemical compounds present in red and black soil

\begin{tabular}{|c|c|c|c|c|c|c|c|}
\hline \multirow{2}{*}{$\begin{array}{l}\text { Sl. } \\
\text { No }\end{array}$} & \multirow{2}{*}{ Compound } & \multicolumn{2}{|c|}{ Content, \% } & \multirow{2}{*}{$\begin{array}{l}\text { SI. } \\
\text { No }\end{array}$} & \multirow{2}{*}{ Compound } & \multicolumn{2}{|c|}{ Content, \% } \\
\hline & & Red soil & Black soil & & & Red soil & Black soil \\
\hline 1 & $\mathrm{Na}_{2} \mathrm{O}$ & 3.95 & 0.273 & 14 & Co & 0.406 & 0.441 \\
\hline 2 & $\mathrm{MgO}$ & 0.654 & 3.86 & 15 & $\mathrm{Ni}$ & 0.004 & 0.006 \\
\hline 3 & $\mathrm{Al}_{2} \mathrm{O}_{3}$ & 26.3 & 21.6 & 16 & $\mathrm{Cu}$ & 0.274 & 0.282 \\
\hline 4 & $\mathrm{SiO}_{2}$ & 57.5 & 53.4 & 17 & $\mathrm{Zn}$ & 0.005 & 0.023 \\
\hline 5 & $\mathrm{P}_{2} \mathrm{O}_{5}$ & 1.13 & 0.204 & 18 & $\mathrm{Ga}$ & 0.001 & 0.001 \\
\hline 6 & $\mathrm{SO}_{3}$ & 0.258 & 0.162 & 19 & $\mathrm{Rb}$ & 0.007 & 0.008 \\
\hline 7 & $\mathrm{~K}_{2} \mathrm{O}$ & 1.78 & 0.798 & 20 & $\mathrm{Sr}$ & 0.004 & 0.017 \\
\hline 8 & $\mathrm{CaO}$ & 0.791 & 10.4 & 21 & $Y$ & 0.004 & 0.002 \\
\hline 9 & $\mathrm{Fe}_{2} \mathrm{O}_{3}$ & 4.70 & 6.75 & 22 & $\mathrm{Zr}$ & 0.013 & 0.010 \\
\hline 10 & $\mathrm{Cl}$ & 1.45 & 0.071 & 23 & $\mathrm{Nb}$ & 0.001 & 0.0005 \\
\hline 11 & $\mathrm{Ti}$ & 0.658 & 1.45 & 24 & $\mathrm{Ba}$ & 0.012 & 0.020 \\
\hline 12 & $\mathrm{Cr}$ & 0.01 & 0.01 & 25 & $\mathrm{Ce}$ & 0.021 & 0.023 \\
\hline 13 & $\mathrm{Mn}$ & 0.067 & 0.093 & 26 & $\mathrm{~Pb}$ & 0.003 & 0.002 \\
\hline
\end{tabular}

Coulombic efficiency

Coulombic efficiency compares the recovery of the coulombs through the external circuit against theoretical coulombs that is present in the organic matter. CMFC-1 showed average CE of $7.69 \pm 1.52 \%$, whereas in CMFC-2 it was $6.39 \pm 1.40 \%$. Higher CE of CMFC-1 than CMFC-2 might have been due to the difference in the CEC of red and black soil and also due to more diffusion of oxygen in case of black soil due to high porosity. In MFCs higher CE is reported with pure inoculum culture and with synthetic wastewater [35]. 


\section{Polarization and Internal resistance}

Polarization curve helps to understand the performance of MFC in terms of power generation and internal resistance. It represents the cell voltage and power density as a function of the current density. Figure 2 shows power and polarization curves obtained using variable resistor box for CMFC-1 and CMFC-2.

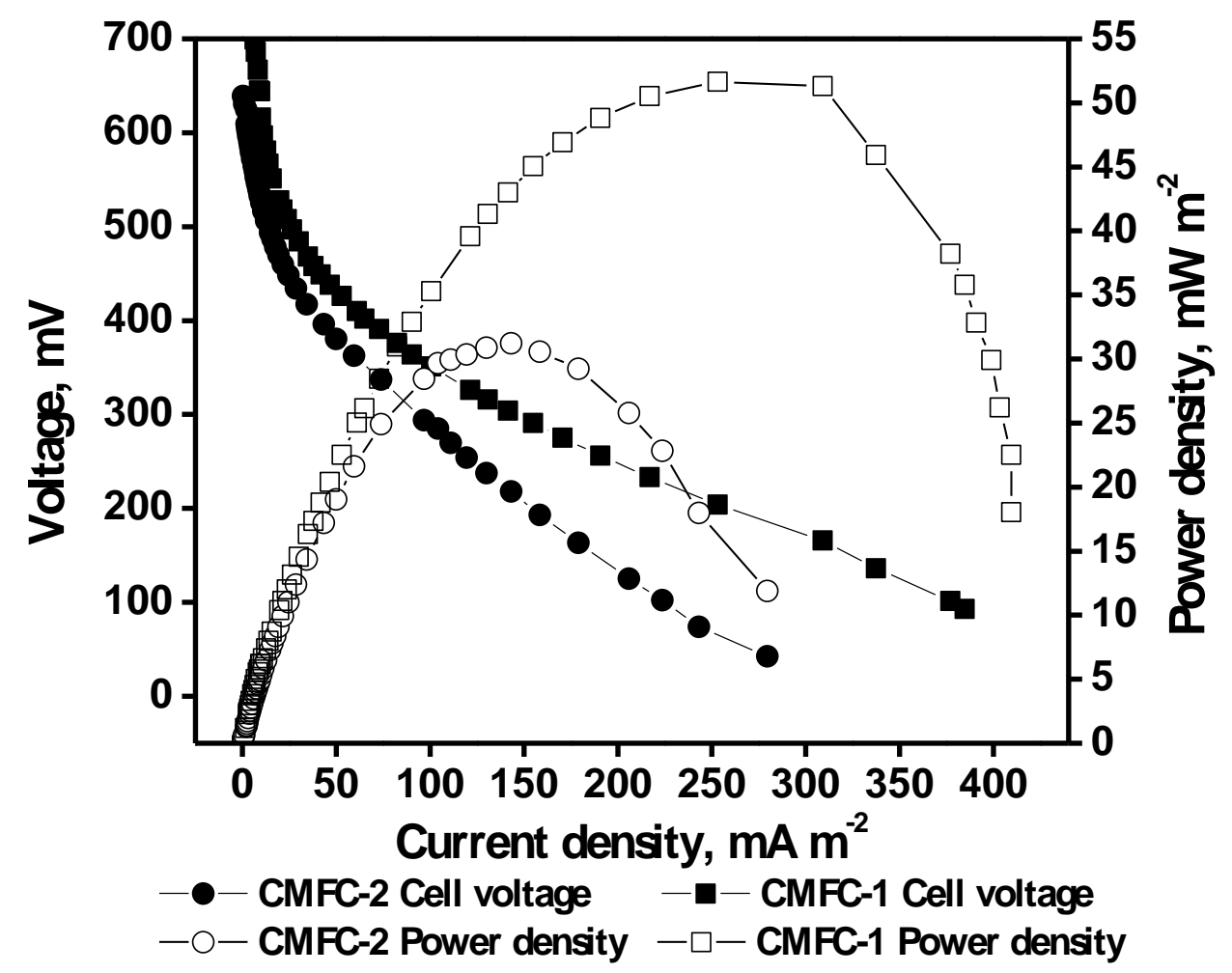

Figure 2. Polarization curve for CMFC-1 and CMFC-2

During polarization, the maximum power density observed for CMFC-1 was $51.65 \mathrm{~mW} \mathrm{~m}^{-2}$ $\left(E=0.204 \mathrm{~V}, R_{\text {ext }}=30 \Omega\right)$ and that of CMFC-2 it was $31.20 \mathrm{~mW} \mathrm{~m}^{-2}\left(E=0.217 \mathrm{~V}, R_{\text {ext }}=50 \Omega\right)$. This indicates that the higher CEC of red soil supported better proton transfer from the anode to the cathode in CMFC-1. Conversely, lower power output observed in CMFC-2 could be attributed to the lesser CEC of black soil used for making separator (Table 1). It is well documented that the cation exchange capacity of soil plays vital role in the proton transfer mechanism in soil [36].

Internal resistances of CMFC-1 and CMFC-2 measured from the slope of the plot of voltage vs. current were $36 \Omega$ and $56.5 \Omega$, respectively. In the region of low current density (Fig. 2) rapid voltage drops were observed in both the MFCs, and in the region of high current density, voltage decreased linearly at lower rate. Lower proton transfer rate and low conductivity of black soil used for making separator of CMFC-2 increased the internal resistance.

\section{Electrode Potential}

Electrode potentials represent the energy level of the electrons at anode and cathode. Electrons move from area of higher potential energy to area of lower potential energy. As the anode has a higher potential energy so electrons move from anode to cathode through an external circuit. During polarization, cathode of CMFC-1 well supported for the reduction reaction up to $0.5 \mathrm{~mA}$ current at $1000 \Omega$ external resistance. However, the cathode potential of CMFC-2 dropped to zero (vs. $\mathrm{Ag} / \mathrm{AgCl}$ ) at $0.25 \mathrm{~mA}$ current at $2100 \Omega$ external resistance, showing inefficiency of cathode for reduction reaction at higher current (Fig. 3). 


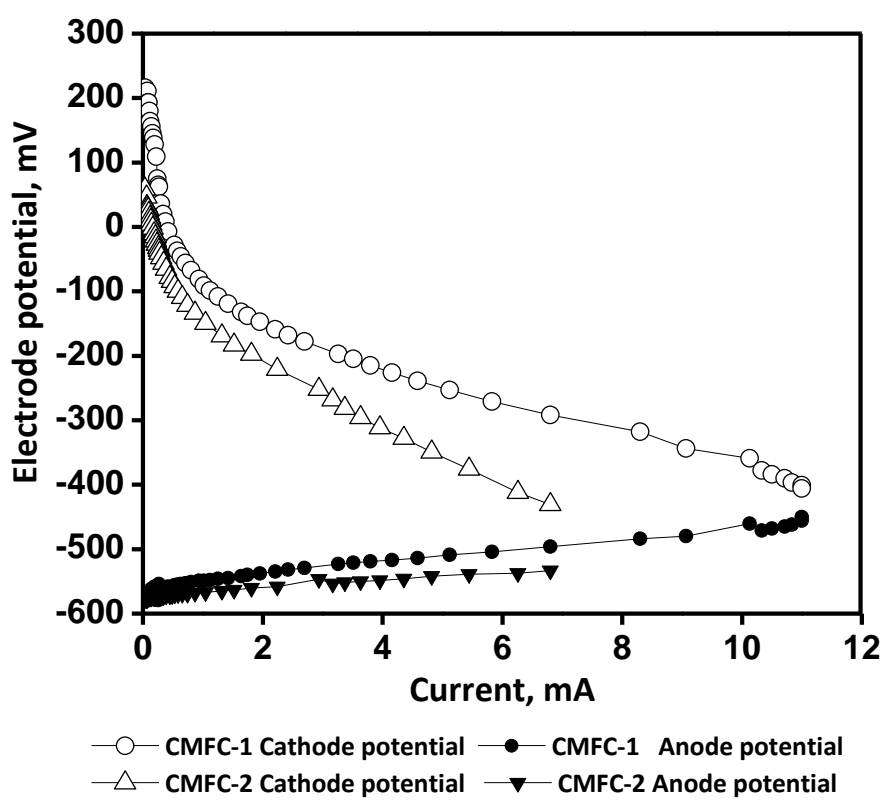

Figure 3. Change of the cathode and anode potentials during polarization in CMFC-1 and CMFC-2

The open circuit potentials (OCP) for anode observed before polarization ( $v s . \mathrm{Ag} / \mathrm{AgCl}$ ) for CMFC-1 and CMFC-2 were $-610 \mathrm{mV}$ and $-580 \mathrm{mV}$, respectively. During polarization, increase in anode potentials was observed in both the MFCs due to transfer of electrons from anode to cathode, thus positive overpotential was observed. However, the anode potentials during polarization in both the MFCs were only slightly increased, indicating better stability of the anodes.

\section{Electrode Kinetics}

Tafel plot analyses were carried out to determine the exchange current density $\left(i_{0}\right)$, charge transfer coefficient $(\alpha)$ and charge transfer resistance $\left(R_{\mathrm{ct}}\right)$. The values obtained from these analyses are summarized in Table 3. Based on the Tafel-type linear equation obtained from the graphs (Figs. 4A, 4B), the slope is $\alpha F / R T$ and the $y$-axis intercept is the logarithm of the exchange current.

For anodic reaction at $25^{\circ} \mathrm{C}$, the slope of Tafel plot is

$$
\mathrm{b}=0.059 / 1-\alpha
$$

and at the same time the slope for cathodic reaction is

$$
\mathrm{b}=0.059 / \alpha(6)
$$

The value of $i_{0}$ represents the rate of exchange current density at equilibrium state when the reaction overpotential is zero. Higher the exchange current $\left(i_{0}\right)$ faster is the reaction rate, resulting in a lower activation energy barrier of forward reaction [37]. The electrode materials used in both the CMFCs were same, however different reaction kinetics at electrodes was observed. The reactions at cathodes were faster than anode. Presence of very high actual surface area of the carbon felt material resulted in producing a low cathodic overpotential [38]. Comparing the $i_{0}$ values for the reduction reactions at cathode of CMFC-1 and CMFC-2, the CMFC-1 with separator made from red soil had better performance. It indicates that the reactions at cathode of CMFC-1 were faster; might be due to the higher transfer of $\mathrm{H}^{+}$ions and other cations in CMFC- 1 , enhancing the reaction rates at cathode. Comparing the anodes of both the CMFCs, reactions at the anode of CMFC-2 were slightly faster than CMFC-1. Apart from the differences in the CEC, the reactions at cathode of CMFC-2 were slower than CMFC-1. This could be probably due to the higher porosity of 
the clayware separator used in CMFC-2, due to which the substrate exchange occurred and oxygen supplied in the cathodic chamber was utilized by the substrate. The exchange current densities of CMFC-1 and CMFC-2 cathodes were 3.38 and 2.05 times more than that of the respective anodes, clearly indicating that the reaction at cathode was much faster than anode.

A

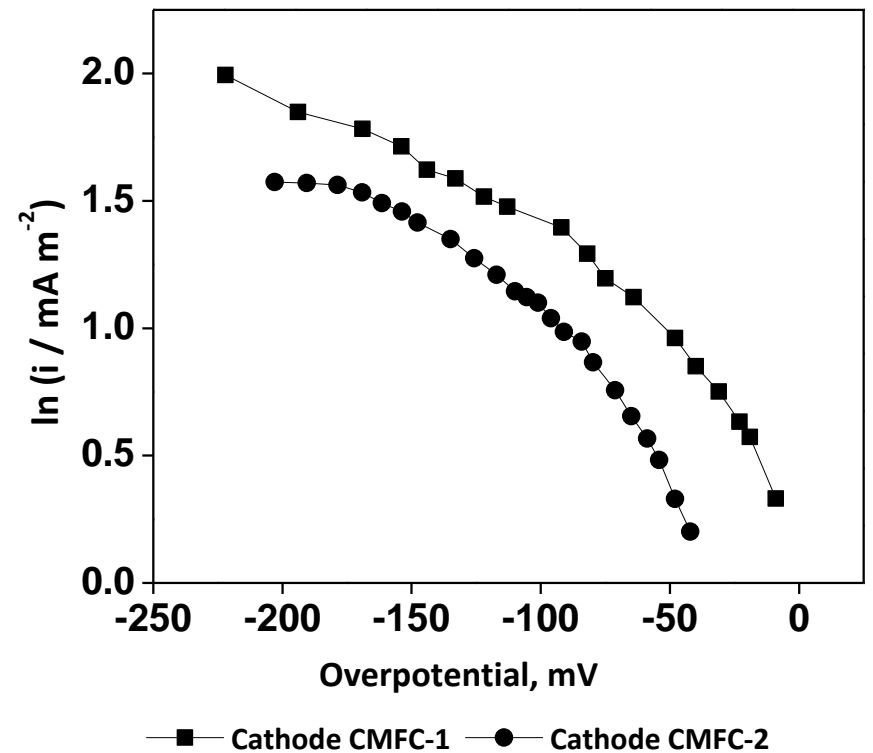

B

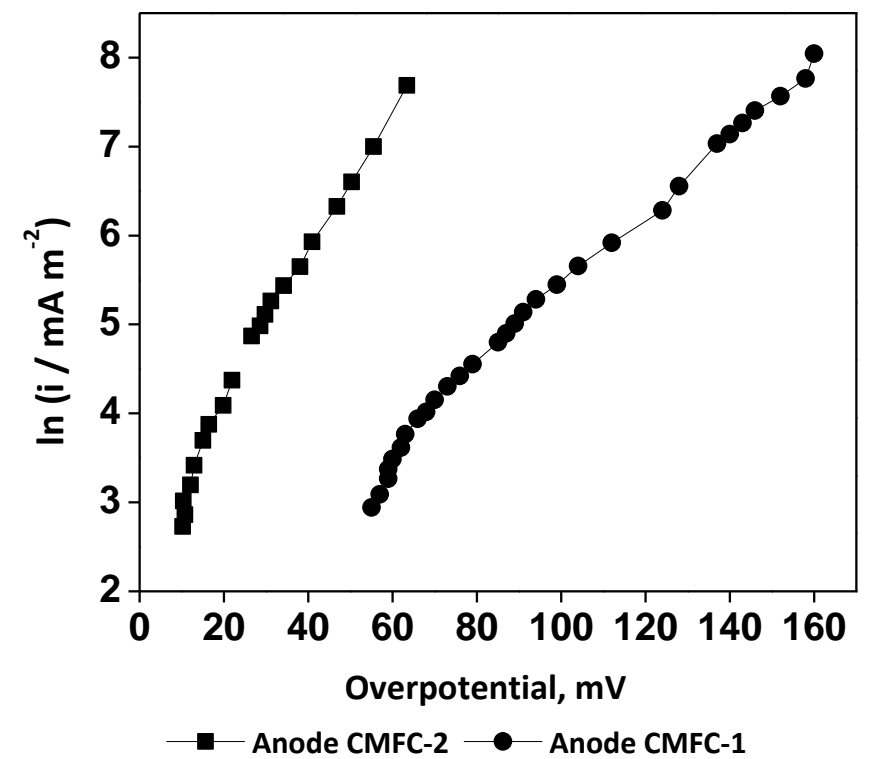

Figure 4. Tafel plots for $\boldsymbol{A}$ - cathode of CMFC-1 and CMFC-2, and $B$ - anode of CMFC-1 and CMFC-2

According to the Butler-Volmer model of electrode kinetics, the charge transfer coefficient $(\alpha)$ is used to describe the symmetry between the forward and reverse electron transfer steps and the magnitude of $\alpha$ ranges in value from 0 to 1 . Charge transfer coefficient signifies the fraction of the interfacial potential at an electrode-electrolyte interface that helps in lowering the free energy barrier for the electrochemical reaction. Lower electron transfer coefficient indicates less activation energy required for the electron transfer, resulting lower activation loss [37]. Charge transfer resistance $\left(R_{\mathrm{ct}}\right)$ represents the capability to resist the transfer of charge from electrodeelectrolyte interface. It is interesting to note that the $R_{\mathrm{ct}}$ and $\alpha$ (Table 3 ) of cathodes for both the MFCs were much lesser than the anode of both the MFCs. 
Table 3. Tafel analysis of CMFC-1 and CMFC-2

Parameter

\begin{tabular}{lcccc}
\hline & Anode & Cathode & Anode & Cathode \\
\hline Exchange current density $\left(i_{0}\right), \mathrm{mA} \mathrm{m}^{-2}$ & 0.60 & 2.03 & 0.74 & 1.52 \\
\hline Charge transfer coefficient $(\alpha)$ & 0.30 & 0.032 & 0.45 & 0.038 \\
\hline Charge transfer resistance $\left(R_{\mathrm{ct}}\right), \Omega \mathrm{m}^{2}$ & 10.70 & 3.16 & 8.67 & 4.22 \\
\hline
\end{tabular}

The $R_{\mathrm{ct}}$ and $\alpha$ values for cathode of CMFC-1 were lower than CMFC-2, which supports that the clayware membrane made from red soil supported better reaction at the cathode. This is because of high cation transported from CMFC-1 to the cathode side, increased the rate of electrochemical transformation with lower electrical energy loss, thus charge transfer coefficient gets reduced. Lower $R_{\mathrm{ct}}$ for anode of CMFC-2 than anode of CMFC-1 indicated that the anode of CMFC- 2 was performing slightly better, as also evident from the exchange current density. However, due to limitations of the cathodic reactions the overall performance of CMFC-2 was inferior as compared to CMFC-1.

\section{Conclusions}

Properties of the clayware separator such as CEC, $\mathrm{pH}$ and electrical conductivity influenced the performance of MFCs. The power generation of MFC having separator made from red soil was better than the black soil, due to high CEC, low pH and higher electrical conductivity of the red soil. Results of Tafel plots showed that lower exchange current density and higher charge transfer resistance of anodes compared to cathodes, contributed towards more activation loss in both the MFCs. In spite of similar electrode materials in both CMFCs, variation in electrode kinetics accentuate effect of properties of separator on the performance of CMFCs. Detailed studies on the mineral composition of soils are required to enhance the CEC for further improving power generation of MFC made with such low cost clayware separator. Development of such efficient and cheaper separator material will help in drastically reducing fabrication cost of MFC for field implementation.

Acknowledgement: Grants received from Department of Science and Technology, Government of India (File No. DST/TSG/NTS/2010/61) to undertake this work is duly acknowledged.

\section{References}

[1] B. E. Logan, B. Hamelers, R. Rozendal, U. Schröder, J. Keller, S. Freguia, P. Aelterman, W. Verstraete, K. Rabaey, Environ. Sci. Technol. 40 (2006) 5181-5192.

[2] D. A.Lowy, L. M. Tender, J. G. Zeikus, D. H. Park, D. R. Lovley, Biosens. Bioelectron. 21 (2006) 2058-2063.

[3] K. Rabaey, W. Ossieur, M. Verhaege, W. Verstraete, Water Sci. Technol. 52(1) (2005) 515523.

[4] K. Rabaey, W. Verstraete, Trends Biotechnol. 23 (2005) 291-298.

[5] B. E. Logan, J.M. Regan, Environ. Sci. Technol. 40 (2006) 5172-5180.

[6] Y. Tian, C. Ji, K. Wang, P. Le-Clech, J. Membr. Sci. 450 (2014) 242-248.

[7] D. Pant, G. Van Bogaert, M. De Smet, L. Diels, K. Vanbroekhoven, Electrochim. Acta 55 (2010) 7710-7716.

[8] R. A. Rozendal, H. V. Hamelers, C. J. Buisman, Environ. Sci. Technol. 40(17) 5206-5211. 
[9] M. M. Hasani-Sadrabadi, S. H. Emami, R. Ghaffarian, H. Moaddel, Energ. Fuel 22 (2008) 2539-2542.

[10] C. Felice, S. Ye, D. Qu, Ind. Eng. Chem. Res. 49 (2010) 1514-1519.

[11] D. H. Park, J. G. Zeikus, Biotechnol. Bioeng. 81 (2003) 348-355.

[12] H. N. Seo, W. J. Lee, T. S. Hwang, D. H. Park, J. Microbiol. Biotechnol. 19 (2009) 1019-1027.

[13] M. Behera, M. M. Ghangrekar, Water Sci. Technol. 64 (2011) 2468-2473.

[14] F. F. Ajayi, P. R. Weigele, Bioresour. Technol. 116 (2012) 86-91.

[15] J. Winfield, J. Greenman, D. Huson, I. leropoulos, Bioprocess Biosyst. Eng. 36 (2013) 19131921.

[16] V. V. Volk, M. L. Jackson, Clays Clay Mineral. 12 (1964) 281-285.

[17] A. G. Hunt, S. D. Logsdon, D. A. Laird, Soil Sci. Soc. Am. J. 70 (2006) 14-23.

[18] G. C. Gil, I. S. Chang, B. H. Kim, M. Kim, J. K. Jang, H. S. Park, H. J. Kim, Biosens. Bioelectron. 18 (2003) 327-334.

[19] H. Liu, B. E. Logan, Environ. Sci. Technol. 38 (2004) 4040-4046.

[20] K. Raman, M. Mortland, Soil Sci. Soc. Am. J. 33 (1969) 313-317.

[21] M. F. Delbem, T. S. Valera, F. R. Valenzuela-Diaz, N. R. Demarquette, Quím. Nova 33 (2010) 309-315.

[22] J. H. Chang, J. H. Park, G. G. Park, C. S. Kim, O. O. Park, J. Power Sources 124 (2003) 18-25.

[23] B. Liao, M. Song, H. Liang, Y. Pang, Polymer 42 (2001) 10007-10011.

[24] J. Derome, A. J. Lindroos, Environ. Pollut. 99 (1998) 225-232.

[25] G. P. Matthews, G. M. Laudone, A. S. Gregory, N. R. A. Bird, A. D. G. Matthews, W. R. Whalley, Water Resour. Res. 46 (2010) W05501.

[26] M. Behera, P. S. Jana, M. M. Ghangrekar, Bioresour. Technol. 101 (2010) 1183-1189.

[27] G. S. Jadhav, M. M. Ghangrekar, Appl. Biochem. Biotech. 151 (2008) 319-332.

[28] APHA, Standard methods for examination of water and wastewater. American Public Health Association, American Water Works Association, Water Environment Federation, $20^{\text {th }}$ ed., Washington, DC 1998.

[29] C. Picioreanu, I. M. Head, K. P. Katuri, M. van Loosdrecht, K. Scott, Water Res. 41 (2007) 2921-2940.

[30] Indian standards, IS:2720-Part 26, Methods of test for soils (Determination of $\mathrm{pH}$ value), Bureau of Indian Standard, New Delhi, India 1987.

[31] Indian standards, IS:14767, Methods of test for soils (Determination of specific electrical conductivity), Bureau of Indian Standard, New Delhi, India, 2000.

[32] Indian standards, IS:2720-Part 24, Methods of test for soils (Determination of cation exchange capacity), Bureau of Indian Standard, New Delhi, India, 1976.

[33] A. J. Bard, L. R. Faulkner, Electrochemical methods: principles and applications, John Wiley \& Sons, Inc. New York, 2001.

[34] H. Quiquampoix, J. Soil Sci. Plant Nutr. 8 (2008) 75-83.

[35] P. Aelterman, K. Rabaey, H. T. Pham, N. Boon, W. Verstraete, Environ. Sci. Technol. 40 (2006) 3388-3394.

[36] B. Ulrich, J. Plant Nutr. Soil SC. 149 (1986) 702-717.

[37] S. Srikanth, M. Venkateswar Reddy, S. Venkata Mohan, Bioresour. Technol. 119 (2012) 241251.

[38] Q. Deng, X. Li, J. Zuo, A. Ling, B.E. Logan, J. Power Sources 195 (2010) 1130-1135.

C 2014 by the authors; licensee IAPC, Zagreb, Croatia. This article is an open-access article distributed under the terms and conditions of the Creative Commons Attribution license (http://creativecommons.org/licenses/by/3.0/) (cc) BY 